\title{
PESCADORAS EN LA CALETA DE CHORRILLOS-LIMA ${ }^{1}$
}

\author{
CARMEN CAZORLA ZEN ${ }^{2}$ \\ UNIVERSIDAD NACIONAL SAN CRISTÓBAL DE HUAMANGA \\ cazorlazen@yahoo.com
}

\section{RESUMEN}

Se describe y analiza algunos elementos de la pesca artesanal y la participación de las mujeres como protagonistas. Así mismo, entender que piensan las pescadoras de su trabajo, si existe algún tabú en torno a su participación y cómo responden ellas frente a las restricciones que se gestan en torno a esta actividad económica.

Palabras clave: Pesca artesanal, trabajo femenino, cosmovisión

\section{Abstract}

It describes and analyzes some elements of artisanal fisheries and participation of women as protagonists. Also, understand that fisherwomen think of their work, if there is any taboo around their participation and how they respond against the restrictions that are developing around this economic activity.

KEYwoRds: Artisanal fisheries, women's work, worldview

1. El artículo se desprende de la investigación etnográfica realizada en la caleta de Chorrillos- Lima, entre los meses de agosto a diciembre del año 2015.

2. Arqueóloga egresada de la Universidad Nacional San Cristóbal de Huamanga. Magister en Antropología en la UNMSM, trabaja como docente de Investigación académica en la Universidad Tecnológica del Perú. 


\section{INTRODUCCIÓN}

Ciertos estereotipos en el mundo de la pesca señalan que esta actividad es exclusivamente masculina, pues lo riesgoso de este trabajo lleva a pensar que los varones son los únicos que podrían afrontar los peligros del mar. No obstante, encontramos que algunas mujeres si tienen un real acercamiento al mar y ejercen la actividad pesquera, incluso en ocasiones a organizar incursiones pesqueras exclusivamente femeninas con una que otra ayuda masculina. En esta exposición, plantearemos precisamente algunas experiencias de mujeres pescadoras que contrasta este misterioso mundo de la vida marina. Este trabajo es un acercamiento etnográfico a la presencia femenina en el mundo de la pesca. En una primera parte desarrollaremos una pequeña presentación sobre la cuestión femenina en el mundo de "trabajos pesados" y reconocidos como masculinos, y esto lo abordaremos desde los debates de género; en un segundo momento observaremos alguna información sobre el mundo de la pesca en la historia regional; y finalmente expondremos la experiencia de una pescadora chorrillana desde un acercamiento etnográfico.

\section{La Caleta de Chorrillos}

Chorrillos es un centro de acopio de especies marinas para consumo humano con uso de 15 millas de la costa como espacio de operación de desembarque. La descarga de la flota artesanal se ejecuta en la infraestructura portuaria operada por la capitanía de puerto. Los pescadores artesanales están representados por la Asociación Sindicato de Pescadores Artesanales "José Silverio Olaya Balandra".

\section{Antecedentes Históricos de la Pesca Limeña}

La importancia de la actividad pesquera en esta parte de la región se inicia en la época prehispánica y durante la colonia se incentivó por el crecimiento demográfico y las migraciones. Esto posibilitó el desarrollo de la cultura en los valles bajos de la costa. Flores Galindo (1981) menciona que algunas de las caletas de la costa central se fundaron en la colonia como producto de las migraciones de agricultores por el proceso de expansión de las haciendas, como es el caso de Chorrillos, su fundación data de 1688, sus pobladores fueron inicialmente indios de Huacho y agricultores migrantes por la expansión de siembra de caña de azúcar en Surco. La proliferación de las caletas en la costa central propone al autor, responde a la presión de los españoles sobre los indios que vieron en la pesca un espacio de libertad, ya que se ubicaban en espacios poco accesibles. La actividad de la pesca fue un recurso utilizado para mantenerse alejados de las presiones tributarias de los españoles sobre los indios, mantener tradiciones culturales que habían estado siendo reprimidas y encuentran un espacio donde la iglesia tiene poco acceso y pueden seguir manteniendo sus espacios de ritualidad: «Los pescadores vivían, pues, alejados de las ciudades y de las haciendas, lo que significaba también vivir a una prudente distancia de administradores coloniales (recolectores de tributos, corregidores o intendentes) y también de curas e iglesias» (Galindo 1981:163).

También es importante considerar los registros arqueológicos de este espacio como parte del complejo de Armatambo que se ubica en la margen izquierda del valle bajo del río Rímac, las crónicas más tempranas describen la importancia de este espacio con ocupaciones del señorío Ichma. De acuerdo a las investigaciones de Díaz y Vallejo (2002) Armatambo en la época inca se constituyó en un centro urbano de gran importancia en el esquema de organización de la costa central, y también por la cercanía al complejo de Pachacamac:

«...era este postrero pueblo el mayor de todos, y estaba asentado en la falda oriental del 
grande población; veanse las casas del Cacique con las paredes pintadas de varias figuras, una muy suntuosa guaca o templo y otros muchos edificios que todavía están en pie sin faltarles más que la cubierta [...] a estos pueblos como cabeza de gobierno obedecían innumerables lugarejos de corta vecindad que habían en sus límites de los cuales apenas queda memoria, ni aun de los nombres que tenían más que una infinidad de paredones y adoratorios que hay por todo el valle. (Cobo 1882[1639]).» (Díaz y Vallejo,2002: 360)

La cercanía a Pachacamac permitió que estos agricultores ahora convertidos en pescadores continuaran sus procesos rituales, mirando al mar como una expansión de tierra firme, por ello el uso de algunos términos que se utilizan en la actividad pesquera (hasta la actualidad): mirar al mar como una chacra, los pescadores de acuerdo a las especies geo-referencian como parcelas y cada pescador tiene una chacra en el mar. La captura también está relacionada con la cosecha. Así mismo la concepción en torno a la extensión de la masa de agua salada: Mar, en la cosmovisión de las sociedades costeras se encuentra asociada al género femenino. En el mundo andino es la "paqarina», espacio donde se forma la vida, al igual que tierra firme (mamapacha) esto se demuestra en la iconografía prehispánica, en los mitos de origen que narran la llegada de los dioses fundadores.

Así mismo, la población de especies marinas se describe a través de un mito relacionando a Pachacamac y que fue recopilado por el cura extirpador de idolatrías Francisco de Ávila (¿1598?), trata de una mujer "Urpay Wachaq" madre de dos de las hijas de Pachacamac, quien criaba peces dentro del palacio y tras un evento de conflicto con Cuniraya posibilita la proliferación de especies marinas: «En aquel tiempo, dicen, no existía ni un solo pez en el mar [cocha mama] únicamente la mujer a quien llamaban «la que pare palomas» criaba [peces] en un pequeño pozo que tenía en su casa. Y el tal Cuniraya, muy enojado: « ¿por qué esta mujer visita a Cavillaca en el fondo del agua?» diciendo, arrojó todas las pertenencias de Urpayhuachac al gran mar. Y solo desde entonces, en el lago grande, se criaron y aumentaron mucho los peces». (Ávila 2006 [i1598?]: 21)

La importancia de este muelle se sustenta en el factor socio-cultural durante la colonia que permitió asentarse a una población de agricultores migrantes que miraban al mar como un repositorio de tradiciones y rituales frente a la represión de la iglesia católica. Trasladaron festividades, recrearon nuevos mitos porque provenían de diversos grupos étnicos donde el mar es un elemento vital generadora de lluvias, manantiales, ríos y sus dioses tienen la capacidad de vivir dentro y fuera del mar.

\section{El Trabajo Femenino y la Desigualdad, el Debate Teórico}

La mirada de Sherry Ortner con respecto a la naturaleza anatómica entre hombres y mujeres en diferentes culturas, nos permite comparar la actividad pesquera de las mujeres con sus pares los pescadores: «El estereotipo es que en cualquier situación exterior que requiera ejercicio muscular, los hombres se desenvolverán mejor que las mujeres. Entonces la tipificación del genero atribuye a los varones unos roles que tienen alguna conexión con todo ello» (Ortner 1979:135)

Esta manera de clasificar el trabajo de las pescadoras en función a las diferencias anatómicas con sus pares no tiene una correspondencia concreta ya que no se considera elementos fundamentales como el tiempo de trabajo que efectúan las mujeres. Lo que se realiza es una clasificación simplista en base a las diferencias biológicas en función a cuánto puede producir una mujer en el laboreo pesquero.

No pretendemos aplicar universales culturales y humanos, y ver la posición subordinada de la mujer con respecto al hombre, pero creemos que en esta caleta los patrones de conducta y socialización con respecto a la mujer han permitido establecer mecanismos de legitimación que instituyen los procesos de interrelación y valoración con respecto a la división del trabajo. Sin embargo, estos 
mismos patrones se repiten en otras sociedades pesqueras. Es así que en la investigación realizada por De Oliverira y Sefnner en el municipio de São José do Norte en el extremo sur de Brasil (20102013) encuentran que las mujeres pescadoras han ido incorporándose a esa actividad primero como auxiliares en la producción pesquera de sus esposos pescadores y posteriormente como pescadoras reclamando regímenes de igualdad y reconocimiento como pescadoras, que sin embargo se está muy lejos del ideal de equidad de género, pues en ella se evidencia una fuerte estructura patriarcal:

«Las mujeres necesitan presentar motivos justificados para dedicarse a la pesca. En cambio, para los hombres, basta auto-nombrarse como pescadores para obtener reconocimiento. Fue posible percibir cierta invisibilidad femenina en la pesca y la subordinación de las mujeres a sus maridos, resultado de relaciones desiguales de poder» (De Oliveira y Sfenner 2013:69)

Esta misma figura aparece en México en la costa del pacífico norte; bahía tortugas, bahía asunción, la bocana y punta abreojos, las mujeres ejercen actividades pesqueras en el proceso de la producción mas no en la pesca misma:

«La principal actividad económica en la zona Pacífico norte es la pesca de langosta, abulón y escama. Existe una división del trabajo por género en la actividad pesquera, según la cual, el hombre captura y la mujer participa en parte del proceso. Si bien algunos hombres toman parte en las labores de la planta de procesamiento, ninguna mujer trabaja directamente en el mar» (Soares, Castoreña y Ruiz 2005:)

La investigación de la antropóloga Amelia García (2001) en la caleta de San Andrés- Pisco, propone que la participación de la mujer en la actividad pesquera estará condicionado por la cultura predominante en cada caleta, considera algunos aspectos importantes: el origen de la comunidad pesquera y como se desenvuelve en el espacio socio-económico, todo ello concretará el desempeño de la mujer en la pesca.

Estas diferencias socialmente determinadas se manifiestan por ejemplo al acceder a los espacios políticos o de organización en el que las mujeres tienen una participación limitada o subordinada. En la caleta de Chorrillos las mujeres mencionan que no han asumido cargos gerenciales en el sindicato de pescadores: « Nunca ha entrado una mujer a dirigir el sindicato. Que van a querer, ellos son pescadores, no las dejarían. (...) tampoco me dan nada a mí, sólo a mis hijos porque ellos son pescadores» (Pascuala Cuya, 84 años Chorrillos 2015)

En este sentido, Sherry B. Ortner (1979) reflexiona acerca de la universalidad de la subordinación femenina y parte el análisis de un problema: ¿cuáles podrían ser las pruebas de que una cultura en concepto considera inferiores a las mujeres? y propone algunos tipos de datos que permiten comprender estas diferencias: primero, las valoraciones de subordinación de la mujer con respecto al hombre tienen una correspondencia con la construcción de la ideología cultural que asignan funciones a las mujeres en su entorno social otorgándoles menos prestigio que el concedido a los hombres. Segundo, los artificios simbólicos, como atribuirles una cualidad contaminante; y tercero, los ordenamientos socio estructurales que excluyen a la mujer de participar o tener contacto con determinadas esferas donde se supone que residen los poderes sociales. Es decir, la construcción cultural genera elementos que permiten colocar a la mujer en un espacio de subordinación. La lucha continua de búsqueda de equidad de género tendrá éxito cuando se entienda que esta involucra a hombre y mujer confrontando a ambos como un elemento en conjunto necesarios para la supervivencia de la especie 


\section{Las Mujeres en Sociedades Pesqueras}

Las mujeres en sociedades pesqueras han desarrollado diversas actividades relacionadas a la pesca misma o actividades derivadas de esta: venta del recurso hidrobiológico, elaborar y reparar redes, bolsos de pesca (Carcal), selección de carnada, prestar servicios de limpieza a botes y chalanas, elaboración y venta de artesanía. Como pescadoras, a menudo parte por razones de subsistencia y la actividad se realiza con la participación de la familia nuclear. La zona de pesca no rebasa las cinco millas y se especializan en una determinada especie que les permite mantener un equilibrio económico y la competencia se reduce con los pescadores ya que trabajan directamente confrontados con ellos. La pesca artesanal en el Perú de acuerdo al Decreto Supremo 005-2012 promulgado por el Ministerio de la Producción (Produce) permite acceder entre 5 a 10 millas para la pesca de menor escala (de 10 a $32 \mathrm{~m}^{3}$ de bodega) (IMARPE, 2015). De acuerdo al trabajo de campo realizado en la Caleta de Chorrillos, las mujeres que se dedican a la pesca en pocas ocasiones se arriesgan a la pesca de altura más allá de las 7 millas, por el riesgo que implica manipular la chalana y se requiere contratar a hombres para realizar una buena cosecha ${ }^{3}$. Sumado a la inequidad de redistribución de ingresos que apertura más las brechas de trabajo en la pesca entre las mujeres y los hombres. Las mujeres al ser contratadas para trabajar en un bote o chalana recibirán menos dinero que un hombre por un discurso de clasificación social, ya sea por su condición de género o poniendo en plataforma su situación de subordinadas. Esta desvaloración del trabajo ejecutado por las mujeres en las chalanas y botes se basa en las ideas de género relacionada a la clasificación en las diferencias anatómicas. Los trabajos que requieren mayor fuerza son asignados a los hombres y obtienen un monto mayor de pago. Sin embargo, las pescadoras cumplen una doble función como actores de subsistencia: proveedoras del sustento económico y encargadas de la crianza de los hijos y mantenimiento del hogar. La pesca en su mayoría se realiza en dos horarios: $3 \mathrm{am}-6 \mathrm{am}$. y $17 \mathrm{hr}$. $21 \mathrm{hr}$. Las horas fuera del mar se realizan actividades paralelas entre el comercio y la atención de sus hijos:

«En la mayoría de las comunidades, si bien no en todas, los productores primarios suelen ser hombres, mientras que de las mujeres se suele esperar una doble función: primero, como sostenimiento principal de sus hogares e hijos y, segundo, como responsables de la elaboración, comercialización y distribución del pescado.» (McGoodwin, 2002:10).

Es así que las mujeres no realizan el trabajo de la pesca como una actividad complementaria a su quehacer diario, sino que es una fuente primaria de ingreso económico. El proceso de transformación y comercialización del recurso marino se ejecuta con la familia y el 90\% del producto extraído se dedica a la venta porque eso les genera mayores ingresos. Para la alimentación se destina los peces de menor valor en el mercado:

«El ojo de Uva es un pescado caro, cuando lo sacamos no lo comemos. Eso puedes venderlo aquí a unos 40 soles si es grande, con esa plata podemos comprar los útiles de colegio, así juntamos. No lo comemos, quién se come 40 soles» (Juana, 32 años Chorrillos 2015)

La forma como se percibe a las pescadoras en la caleta de Chorrillos es posicionarlas en aparente igualdad con sus pares los pescadores, es decir ellas pierden su imagen como mujeres y se transforman en una figura masculina "machas", de esa manera ellas pueden competir abiertamente en el trabajo. Esta forma de mirarse también está en el discurso de las mismas mujeres.

3. Cosecha: Pesca. (Casma). Extraer del mar los productos marinos que la naturaleza provee (Pastor 2012: 135); explica que este término se deriva porque algunos pescadores en Casma son o han sido agricultores y existe una relación lógica entre el espacio suelo y mar. Esta expresión también es utilizado en la caleta de Chorrillos porque es parte del lenguaje de los pescadores. 


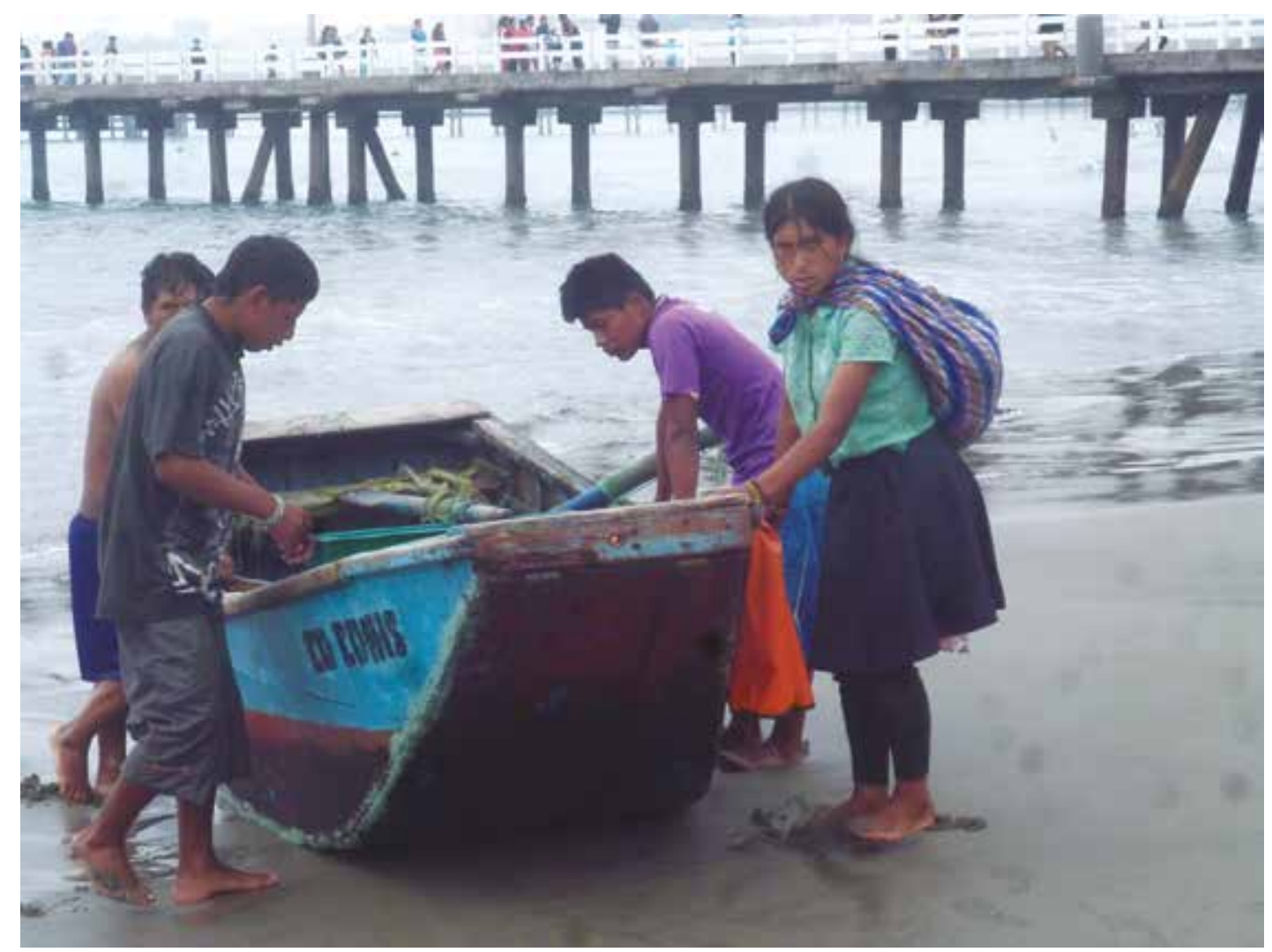

Foto: Cazorla, Chancay 2015.

Entrevistamos a la señora Pascuala Cuya quien ha trabajo como pescadora muchos años:

«Yo trabajo en la pesca desde los quince años, yo he chivateado bastante acá, un hombre mismo era yo, porque antes se pescaba diferente te parabas en la esquina del bote y veías la mancha de pescado, entonces tirabas la red y después tenías que estar volteando para que se enrollara. Mi red era de hilo, recogías lindos peces, ahora usan de nylon pero antes era de hilo (...) mi abuelo, mi papá, mi mamá mis hijos siempre hemos sido pescadores toda mi familia (...) yo soy la única dentro de mis hermanas que ha entrado al mar. Ellas trabajan en el mercado con pescados, yo nada más he sido la macha, porque me gusta el mar, especialmente cuando está mansito, ese color azul, el agua sube y baja es bonita. Hay redes también para amallar» (Pascuala Cuya, 84 años Chorrillos 2015)

En la actividad pesquera de la Caleta de Chorrillos la percepción de relaciones de género construidas desde las mujeres para comprender lo que representa ser hombre o mujer creemos que responde a la forma como se construyen las relaciones socioeconómicas donde las mujeres aparecen como las que menos aportan económicamente en las subsistencia del hogar, es decir tienen un ingreso pasivo porque trabajan pocas horas, el ingreso de la venta es menor al obtenido por los hombres, etc. (no se considera el trabajo ejercido en la casa). El esposo de la señora Pascuala era un mecánico de motores, no ejercía el trabajo de la pesca, el mayor ingreso económico en la familia era producto del trabajo de la pescadora, es decir el ingreso activo provenía de ella, sin embargo eso no se percibe en el discurso de la comunidad pesquera. 


\section{Doña Pascuala Cuya, Pescadora de la Caleta de Chorrillos}

En la Caleta de Chorrilllos encontramos a doña Pascuala Cuya de 84 años, una mujer que se ha dedicado a trabajar como pescadora artesanal desde los quince años, tuvo 10 hijos, tres de ellos fallecidos, 42 nietos, 17 bisnietos y dos tataranietos. Es una de las pocas mujeres en la caleta que se dedicó a la pesca de forma activa y continua hasta los 70 años, logrando legitimar su actividad obteniendo una inscripción y carnet de pescadora en el sindicato de pescadores de Chorrillos:

«Las mujeres si pueden entrar a la Mar. Algunas mujeres no les consienten pero yo les mandaba a la mierda y me embarcaba, sino que acá les prohíben, pero he tenido hasta carnet de pescador. Yo siempre he pescado aquí nada más, pero a veces entraba para sacar el calamar, salía a las tres de la mañana hasta la tarde que volvía, llevaba frutas y pan para comer, como un pescador pues»

Este proceso de legalización del trabajo como pescadora le ha permitido tener participación dentro del sindicato (como pescadora, no en la dirigencia) y participar en el sistema de control de producción y desembarque a nivel artesanal de subsistencia, participar en reuniones, ver las confrontaciones entre "pinteros", "rederos", "cangrejero" etc. Los años dedicados a este trabajo le han permitido un espacio de reconocimiento por la comunidad de pescadores.

«Yo, cuando desembarcaba salía orgullosa sacando pecho. Los pescadores decían "ahí está la tía Pascuala, la tía Pascuala”, yo respondía alegre con lisuras, mentaba la madre. Cuando a una le gusta no lo suelta, yo misma como hombre salía. Yo soy la única que ha salido a la Mar aquí. Además yo era viva salía solo cuando había pesca, Yo sé pescar bien, hasta bomba he tirado y hay que saber tirar, solo a los ocho minutos, una vez que tiras ahí se levanta el pescado, entonces a mí me dieron un carcal, que no era así y yo llena y llena tanto el carcal que a la hora de sacar ya no podía, tuve que pedir ayuda»

La comunidad pesquera también reproduce desigualdades estructurales, la autonomía que obtienen las mujeres al ejercer el trabajo como pescadoras así como doña Pascuala es limitada, porque existe jerarquización social, técnica y económica. Esto se percibe en la forma de distribución del recurso pesquero. En el caso de Doña Pascuala ella era dueña de tres embarcaciones "chalanas" y el trabajo se ejercía a nivel familiar por lo tanto la distribución de la captura era equitativa ya que están estrechamente vinculados, sin embargo dentro de la comunidad pesquera, del sindicato aparece invisibilizada. Las otras mujeres que trabajan para terceros en el proceso de: producción, transformación del recurso marino y el comercio, el sueldo o ganancia es fluctuante varía de acuerdo a la capacidad de captura y la recurrencia de salidas al mar. Ante esto tienen que generar mecanismos de supervivencia en un mercado totalmente desigual entre hombres y mujeres: «Yo, salía con chalana, con botes a las justas podía mover pero salía pero necesitaba fuerza. Solo cuando estaba embarazada no salía porque necesitas fuerza. Para mantenerme tenía otro negocio. Antes la Mar se venía de un momento a otro no es como ahora que te avisan, entonces cuando pasaba eso nosotros con mis hijos salíamos ayudar a los otros pescadores, las redes, las chalanas teníamos que jalar, cuidando para que no se rompa las embarcaciones, las redes eran de hilo de cáñamo o pabilo, ahora ya es de nylon »

En su mayoría los pescadores mantienen como única ocupación y fuente de ingreso a la pesca que no se limita sólo a la captura de especies. Las horas que se encuentran fuera del mar son rederos, vendedores de pescado, reparan los botes y chalanas, en el caso de la entrevistada y las familias de otros pescadores poseen un establecimiento de venta de comida con productos marítimos, que les permite generar mayores ingresos y complementar la economía familiar.

Doña Pascuala menciona que su familia ha tenido buenos tiempos de pesca ya que está involucrada la familia en el proceso de captura y distribución, cuando habido temporadas bajas con la pre- 
sencia del fenómeno del niño han podido sobreponerse porque tenían acumulado un capital familiar y han aprendido a usar las nuevas especies que traen las aguas calientes y colocarlas en el mercado. Estas destrezas han ido transmitiéndose de padres a hijos por generaciones y les permite a la economía familiar auto sostenerse en momentos de carencia a la vez que esto se capitaliza y se transforma en mecanismos de cohesión en la comunidad: «El conocimiento técnico especializado constituye un capital social y cultural, en el sentido dado por Bourdieu (1997), por lo que trata de mantenerse dentro de la familia» (Ripsoli 2006:5).

El trabajo como pescadora de doña Pascuala le ha permitido conocer diferentes medios de captura, al igual que los pescadores ella no se ha limitado a una sola especie, ese conocimiento le ha permitido mantener a una familia numerosa:

«Yo he salido con mis hijos a pescar calamar, pero también pejerrey, lisa, jurel, cojinova. El pejerrey es más difícil una vez se ha enredado y para sacar como son chiquitos se enredó todo, pero después me dolían las piernas, la espalda, pero saqué bastante peces de aquí de la Herradura nada más (...) a nosotros nos conviene el fenómeno del niño, por el sol, calienta y las aguas traen otros peces corvinas, otra clase pero también mata otros peces. En invierno me dedicaba a sacar Lorna y en verano toda clase de pescado»

Los "pinteros" o pesca en chalanas procuran capturas de peces de carne blanca que tienen mayor precio en el mercado a diferencia que las embarcaciones más grandes botes o "rederos" quienes ejecutan pesca de altura. Sin embargo frente a la pesca industrial se encuentran en una abismal diferencia económica. El hijo de la señora Pascuala quien también es pescador nos explica que las capturas han descendido en los últimos 20 años por la pesca industrial en perjuicio de la pesca artesanal:

«La pesca ha bajado por la competencia con barcos rusos, mira yo un día hace ya varios años me fui de aquí en bote hasta Ancon pasando por el Callao haciendo pesca de altura, vi casi 40 barcos rusos sacando nuestra anchoveta con aspiradoras, en pesca de altura, eso arrasa con todo chico grande hasta la hueveras con todo. Por eso la pesca ha bajado» (Barraza ,50 años Chorrillos 2015)

En la actualidad en Chorrillos se ejecutan diversos tipos de captura, siendo la capitanía de puerto quien autoriza y fija los turnos especialmente para la captura de corvina. Los pescadores se encuentran agremiados en el sindicato de pescadores José Olaya Balandra. Entre los tipos de captura los pescadores utilizan por ejemplo: los "chinchorros", y es una actividad exclusiva para la captura de corvina, siendo esta la que genera más ingresos. También están las chalanas "cangrejeras" que son operadas por dos o más pescadores y la captura se realiza en las peñerías de la playa en horas de la mañana, los "pinteros" o chalanas cuyos pescadores se dedican a la captura de peces de carne blanca y expenden a restaurantes del malecón, los "pinteros" embarcaciones con cubierta o botes utilizan redes agalleras de cortina y la captura de especies es variada: boniteras, cojinoberas, corvineras, lorneras, pejerreyeras, etc. Los pescadores artesanales en esta caleta se ven en la constante necesidad de adaptarse al cambio climático que actúa directamente en el mar y han aprendido del comportamiento de las aguas y de las especies para poder mantener activa su economía sustentada directamente por la captura de recursos ictiológicos:

«Los pescadores en pequeña escala desarrollan conocimientos profundos, detallados y de orientación funcional de los ecosistemas marinos que explotan y las especies a las que se dedican. » (McGoodwin, 2002:10)

Este proceso de continuo aprendizaje de los pescadores de Chorrillos se sustenta en sus antecedentes históricos. El haber sido una comunidad de agricultores migrantes les ha permitido generar 
mayores estrategias de sobrevivencia ya que no contaban con tierras agrícolas y complementar sus ingresos en las temporadas bajas de pesca. Frente a ello recrearon actividades afines a esta actividad: expendio de alimentos a los pescadores y turistas que acuden al muelle, venta de capturas seleccionadas (peces de carne blanca) para un mercado selecto, artesanías elaboradas con productos marinos: caracoles, piedras, crustáceos disecados, embarcaciones a escala, etc. Especialistas en reparaciones de embarcaciones y redes, turismo y vistas con chalanas a una o dos millas de la playa.

\section{La Mar una EnTidad Viva}

Las aguas se sacralizan por diferentes factores: su posición geográfica, su extensión, propiedades salutíferas, manantes, escases o proliferación de especies, etc. Existe una relación de dependencia directa en su contexto mágico-religioso por la valoración que le asigne cada grupo humano y conlleva a gestar comportamientos sociales, el corpus ritual para mantener el equilibrio.

En este sentido, el carácter sagrado del agua ha sido un elemento central en la mayoría de las cosmovisiones de los pueblos. También se le confiere un género determinado y la explicación a esto se encuentra en los mitos que se han creado en torno a ellas. Así una montaña será identificada con el género masculino y los manantes que se ubican en torno a la montaña serán identificados con el género femenino. « (...) la contraparte femenina de los cerros son los puquios o manantiales vecinos a ellos» (Millones y Millones 2013:36).

La concreción de esa sacralidad se verá reflejado en el culto purificador del elemento en sí o a las deidades que habitan en estos espacios. El agua como elemento fecundador de tierra firme ha sido considerado desde los períodos más tempranos como una entidad viva y se encontraban indisolublemente unidos por una fuerza divina en ellas. En la parafernalia del culto a la tierra se han utilizado productos provenientes de mar, de los ríos o lagunas, así mismo en las ofrendas al mar se acompañaba con frutos de tierra firme. Por ejemplo Millones y Millones (2013) menciona un ritual descrito por un cura evangelizador en la costa central Huacho-Lima se trata de las ofrendas de chicha de maíz antes del recojo del guano de isla se derramaba la chicha en la playa en honor al señor del guano "Huamancanfac" quien fertilizaba los campos de maíz. Estas celebraciones tienen un profundo arraigo cultural especialmente en las relaciones que existen en el universo mágico de la población que habita los espacios costeros y los andes. Existe una correspondencia ritual. Los Apus y Wamanis dioses sagrados de las montañas se alimentaban del "mullu" (Spondylus) y está asociada los rituales de fertilidad. A su vez, los agricultores de los valles bajos colindantes a la franja costera utilizaban la anchoveta para poder abonar sus sembríos. Colocaban una semilla dentro de esta especie y de esa manera se podía asegurar el crecimiento y producción de la planta. Esta interacción y uso de recursos marinos por agricultores permitieron generar hacia el mar cualidades físicas y simbólicas.

La investigación etnográfica realizada en la caleta de chorrillos se sustentó en la necesidad de conocer qué es lo que piensan las pescadoras del trabajo que realizan, si existe algún tabú en torno a su participación en esta actividad económica y cómo responden ellas frente a las restricciones que se gestan en torno a su trabajo. Al realizar las entrevistas con los pescadores y saber qué piensan ellos del trabajo de las mujeres, aparece en primer orden la fuerza que se necesita para ejercer el trabajo. Se asocia el trabajo leve, sencillo como un trabajo "femenino":

«Si pueden entrar a pescar pero se requiere de fuerza para amallar, jalar la red, una chalana no es fácil, necesitas fuerza y las mujeres como mujercitas que son no pueden por eso casi no entrar. A veces de compañía pueden ir, pero trabajo, son pocas, aquí solo una, la tía Pascuala » (Jorge, 64 años Chorrillos 2015) 
El segundo argumento está relacionado con la cosmovisión en torno a La Mar, asociado a la feminidad y por lo tanto existe un rechazo con sus pares y eso se refleja por ejemplo en la "pérdida de la pesca cuando las mujeres ingresan al mar". La investigación del antropólogo Sabino Arroyo en esta misma caleta menciona que:

«Así mismo, es celosa con las mujeres y no acepta su presencia; incluso el pescador evitará copular con su mujer antes de echarse a la mar, para tener en su jornada suerte sin contratiempos es decir «una buena pesca». Todo pescador afirma categóricamente que los hombres muertos en el mar siempre son arrojados desnudos a la orilla: los muertos nunca permanecen en las entrañas de la qochamama». (Arroyo 2003: 144)

Las mujeres miran al mar como sus pares, ellas mencionan el término "La Mar" y la describen como una entidad viva que siente, acciona como una mujer y los temores que enfrenta a ellas al acceder a la pesca de altura:

«La Mar es celosa, te da pero también te quita, hasta todo te puede quitar. Antes había astilleros arriba, ellos arreglaban ahí se lleva las embarcaciones. A mí una vez la braveza del mar me quito mi bote, como nosotros siempre ayudábamos, esa vez yo no vine estaba enferma creo, entonces mi hijo vio mi bote que estaba bien y se puso ayudar a otra gente sería la una de la mañana, cuando terminó fue a ver mi bote y ya no estaba leña, leña estaba. De ahí ya no volví a tener otro bote. Yo he tenido tres chalanas, una me robaron en Ancón, otra acá y el otro está conservada lo tiene mi hijo (...) La Mar de noche da miedo, es oscuro, parece que estarías entrando a la boca de un lobo, por eso tienes que saber cómo entrar y a qué hora entrar. Mi hijo mayor hace pesca de altura y él ha visto ballenas y es peligroso porque puede chocar la embarcación lo voltea» (Pascuala Cuya, 84 años Chorrillos 2015)

El peso cultural de la tradición pesquera artesanal se ha clasificado como un sector masculinizado que limita la incorporación de las mujeres en la pesca en sí, ya sea con los argumentos antes expuestos o con la creación de artificios simbólicos como el atribuirles una cualidad contaminante Ortner (1979) como la menstruación:

«Los pescadores dicen que las mujeres cuando están con la regla no pueden entrar al mar. Eso dicen ellos, pero yo no creo en eso, yo siempre he trabajado así. También la mar menstrua, está con su regla bota una espuma así medio amarillo, rojizo, espeso, con algas» (Pascuala Cuya, 84 años Chorrillos 2015)

El fenómeno biológico conocido como la marea roja o floración de algas que puede ser nocivo para las especies marinas ya que algunos dinoflagelados poseen toxinas y merman la captura de las especies para la producción pesquera, se relaciona con el ciclo fisiológico menstrual en la mujeres. Esta relación se basa al considerar la sangre menstrual como un líquido peligroso o venenoso y requiere el aislamiento de las mujeres durante ese periodo de la actividad pesquera. En diferentes culturas la menstruación ha sido relacionada con el ciclo lunar, en algunos casos el sangrado responde a un evento mágico, de castigo, fertilidad, se asocia a mitos de origen de la humanidad: que la mujer al haber sido mordida en los genitales por un lagarto, culebra, oso, etc. se inició el ciclo fértil y de esa manera la repoblación humana. (Alarcón, 2005:4), Las grandes religiones también consideran a la menstruación como un negativo contaminante y negativo a la sociedad que requiere de un proceso de purificación y seclusión.

Para la señora Pascuala, la menstruación no es un limitante real para el laboreo pesquero ya que considera que es una cuestión fisiológica y que conlleva los mismos cuidados al realizar cualquier trabajo fuera del mar. Su perspectiva es bastante pragmática, porque la necesidad de trabajar y sustentar la familia ha sido un factor primordial para dedicarse a la pesca: 
«Las mujeres deben ser orgullosas de ir a la Mar, es mentira que no se puede. Que se pierde la pesca por la menstruación. Lo único difícil es para poder hacer las necesidades, el hombre es fácil orinar, pero como yo iba siempre con mis hijos entonces me iba atrás y ahí podía orinar» (Pascuala Cuya, 84 años, Chorrillos 2015)

Existen cambios en las relaciones socio-culturales debido a la penetración de la economía de mercado y se han transformado las formas como se piensa la actividad pesquera. El predominio masculino en las diferentes etapas de producción han posibilitado que las mujeres limiten sus actividad a la fase final de la captura de las especies hidrobiológicas.

Las migraciones de agricultores andinos hacia los valles bajos de la franja costera posibilitó que varios elementos culturales se recreen en estos nuevos espacios, como por ejemplo el consumo de la hoja de coca (erythroxylon coca) cumple la misma finalidad que el trabajo agrícola. La Mar está segmentada en parcelas o chacras y la captura se relaciona con la cosecha y para poder mantenerse despierto y con fortalezca los pescadores utilizan la hoja de coca para su masticación. Este producto se compra en el mercado de Chorrillos:

« (...) así tienen que llevar su coca Se mastica hoja de coca con bicarbonato, para aguantar la pesca de altura, si no comen el frio el sueño te gana. Hacen pesca de altura de tres o cuatro días, traen bonito, pez espada, merlín. Para el perico son quince o veinte días. Hacen guardia toda la noche en el barco, jalamos las redes como desde aquí hasta la chalana y más todavía. Yo nunca he usado coca sólo mis hijos, yo sola comía frutas» (Pascuala Cuya, 84 años).

En el imaginario de los pescadores La Mar es una entidad femenina que prodiga de recursos y se requiere de procesos rituales para mantener el equilibrio natural y cultural. En el universo pan andino los dioses y diosas que habitan la zona pelágica han sido transformados por los procesos históricos adquiriendo nuevas identidades, algunas desapareciendo por la imposición de nuevas identidades religiosas. Con el descubrimiento de América llega también un nuevo corpus santoral, las advocaciones cristianas reemplazan algunas deidades locales, pero también algunas se reproducen sutilmente dentro de las imágenes cristianas, a través de código, que recuerdan a los dioses originarios. No es gratuito que algunas caletas del litoral de la costa norte se les hayan asignado una advocación mariana y haya habido una aceptación por parte de los pobladores, porque han extendido el culto a divinidades femeninas asociadas al mar y su productividad. (Prieto 2011:196). Si bien es cierto que San Pedro aparece como el patrón de los pescadores, las advocaciones marianas son importantes en el calendario festivo de los puertos. Por ejemplo en Chorrillos tienen a la virgen del Morro (inmaculada concepción), El puerto del Callao la virgen del Carmen, Puerto de Eten virgen purísima, Huanchaco Virgen de la Candelaria del Socorro, Puerto de Casma la virgen del Carmen, etc. es posible que se trate de una reminiscencia prehispánica, porque en el desarrollo de las grandes culturas pesqueras del Perú aparece la figura femenina asociada al mar. En la iconografía Mochica del valle de Jequetepeque se puede apreciar para la fase tardía la presencia de mujeres que ingresaban al mar para realizar ofrendas. Así mismo, en el periodo Chimu se ha identificado en la cerámica una divinidad femenina asociada a la abundancia y fertilidad. Esta misma deidad está representada en los murales de los palacios de Chanchan Campana (2008).

El arquetipo de las divinidades femeninas en el mar están estrechamente vinculadas a la producción de las especies hidrobiológicas y al ciclo de agua. En función a esto se modela el pensamiento y actitud de los individuos en cada cultura costera y se incorpora como patrones de comprensión de la realidad. A través de representaciones como imágenes, símbolos, mitos, canciones, etc. que están en constante cambio, para luego transformarse en patrones socialmente aceptados. 


\section{Palabras Finales}

El acercamiento etnográfico a una familia de pescadoras artesanales, nos ha permitido comprender algunos elementos importantes de su trabajo y de cómo ellas entienden su participación frente a sus pares. También cómo la cosmovisión pueden alterar, influir en su quehacer diario.

Las pescadoras perciben que el trabajo en el mar produce un impacto diferente en los pescadores, debido a las brechas socio-económicas que relacionan el trabajo femenino como inferior o de menos valor económico. Aunque existen cambios profundos en las relaciones género, en espacios como la actividad pesquera no ha tenido el impacto necesario para posicionarlas en igualdad de oportunidades laborarles y desarrollar una autonomía económica.

En el Perú, entre las culturas agrarias o marinas existe una relación directa con la naturaleza: "mamacocha", "mamapacha", estas poseen atributos de fertilidad y de producción esenciales para el desarrollo de una sociedad y las deidades femeninas representan justamente este arquetipo que se ve reflejado en la actualidad durante las festividades cristianas en la que se observa reminiscencias prehispánicas introducidas en la celebración a las advocaciones marianas.

\section{Agradecimiento}

A la pescadora Sra. Pascuala Cuya y su familia, por permitirme aprender de su actividad económica y su experiencia en La Mar en la caleta de Chorrillos.

\section{Bibliografía}

\section{ÁVILA, Francisco}

2007 Dioses y hombres de Huarochirí [Traducción de José María Arguedas]. Estudio introductorio de Luis Millones e Hiroyasu Tomoeda. Lima: Universidad Antonio Ruiz de Montoya.

ARROYO, Sabino

2003 "Hierogamia cósmica: Culto a Lamarcocha y a San Pedro". En: Revista de Antropología N¹, p. 141-150.Lima

CAMPANA, Cristóbal

2008 "La vida en Chan Chan: Representación y Comunicación". Revista del Museo de Arqueología, Antropología e Historia. $\mathrm{N}^{\circ} 8,11-12$.

CARHUAYO, Amelia

2001 “Género en la pesca artesanal en el Perú”. Investigaciones Sociales. vol. 5, № 7, p. 43-67.

CASTORENA, Lorela; RUIZ, Elena.

2005 "Mujeres y hombres que aran en el mar y en el desierto: Reserva de la Biosfera El Vizcaíno, BCS”. Frontera norte. vol. 17, № 34, p. 67-102.

DE OLIVEIRA, Stela; Seffner, Fernando.

2013 Mujeres en aguas masculinas: trayectorias de pescadoras de São José do Norte, Brasil. Universidade Federal do Rio Grande do Sul. 
DÍAZ, Luisa; Vallejo, Francisco.

2012 “Armatambo y el dominio incaico en el valle de Lima”. En: Boletín de Arqueología PUCP, no 6, p. 355-374. Lima

GALINDO, Alberto

2014 “La pesca y los pescadores en la costa central (s. XVIII)”. Histórica, 5(2), 159-165.

MGOODWIN, James.

2012 Comprender las culturas de las comunidades pesqueras. Clave para la ordenación pesquera y la seguridad alimentaria, FAO. Lima.

MILLONES, Luís y Millones, Mateo

2013 "La humanidad bajo las aguas". Perspectivas latinoamericanas, 10, 35-46.

ORTNER, Sherry

1979 “Es la mujer con respecto al hombre lo que la naturaleza con respecto a la cultura?” Antropología y feminismo. Barcelona. Anagrama, 1979, p. 109-132.

Pastor Marly

2012 Estudio Etnoléxicográfico del léxico de los pescadores de Casma. UNMSM. Lima

PRIETO Oscar

2011 "Las fiestas anuales y quinquenales de la virgen Caldelaria del Socorro de Huanchaco: expresión religiosa de los pescadores de la Costa Norte de Perú". Arqueología y Sociedad N 293- 237. Lima.

Rispoli, Florencia.

2007 Trabajar de Pescador. Aportes desde la Antropología Marítima. 
